\title{
DERIVATION OF ICE SLIDING PROPERTIES FROM THE NUMERICAL MODELLING OF SURGING ICE MASSES
}

\author{
By W. F. Budd, \\ (Antarctic Division, Department of Science, 568 St Kilda Road, Melbourne, Victoria 3004, \\ Australia)

\section{B. J. MaInnes, and I. Smith} \\ (Meteorology Department, University of Melbourne, Parkville, Victoria 3052, Australia)
}

Abstract. It is difficult to deduce sliding properties from the numerical modelling of ordinary glaciers because the flow law of ice is still not known well enough to clearly differentiate sliding from internal deformation of the ice. For glaciers undergoing high-speed surges it appears that the majority of the total speed is due to sliding. Furthermore the average basal shear stress of the ice mass is lowered during the surge. This suggests that surging glaciers can be modelled by incorporating a sliding friction law which has the effective friction coefficient decreasing for high velocities. A relation of this type has been found for ice sliding on granite at $-0.5^{\circ} \mathrm{C}$ by Barnes and others (1 $97 \mathrm{I}$ ) and has also been obtained for rough slabs with ice at the pressure-melting point by Budd and others (1979).

A simple two-dimensional model was developed by Budd and McInnes (1974) and Budd (1975), which was found to exhibit the typical periodic surge-like characteristics of real ice masses. Since the sliding-stress relation for the low velocities and stresses was not known, and was not so important for the surges, it was decided to use the condition of gross equilibrium (i.e. that the ice mass as a whole does not accelerate) together with a single-parameter relation for the way in which the friction decreases with stress and velocity to prescribe the basal shearstress distribution. The low-stress-velocity relation can thus be obtained as a result.

This two-dimensional model has now been parameterized to take account of the threedimensional aspects of real ice masses. A number of ice masses have since been closely matched by the model including three well-known surging ice masses: Lednik Medvezhiy, Variegated Glacier, and Bruarjökull. Since the flow properties of ice are so poorly known-especially for longitudinal stress and strain-rates-the model has been run with two unknown parameters: one a flow-law parameter $(\eta)$ and the other a sliding parameter $(\phi)$. The model is run over a wide range of these two parameters to see if a good match can be made to the real ice masses and if so what the values of the parameters $\eta$ and $\phi$ are for best fit.

The matching of the three above ice masses gave very similar values for each of the two parameters $\eta$ and $\phi$, the value of $\eta$ being within the range of values expected for the flow properties of temperate ice as determined by laboratory experiments. Using the same values of $\eta$ and $\phi$ it is found that the ordinary glaciers modelled so far do not develop surging but that they could do if the value of $\phi$ were increased or if the mass-balance input were sufficiently increased.

For Lednik Medvezhiy a detailed analysis of the friction coefficient with velocity was carried out and it was found that the values required for best fit showed a very close agreement to the sliding friction curve of Barnes and others ( $197 \mathrm{I}$ ) at $-0.5^{\circ} \mathrm{C}$. It is concluded that this type of sliding relation can account for the major features of glacier surge phenomena.

Finally it is apparent that the numerical modelling technique can be used very effectively to test any large-scale bulk sliding relation by the analysis of real surges of ice masses and in addition can provide further insight into the sliding relation in association with other stresses in the ice mass. 


\title{
REFERENCES
}

Barnes, P., and others. 1971. The friction and creep of polycrystalline ice, by P. Barnes, D. Tabor, and J. C. F. Walker. Proceedings of the Royal Society of London, Ser. A, Vol. 324, No. 1557, p. 127-55.

Budd, W. F. 1975. A first simple model for periodically self-surging glaciers. Journal of Glaciology, Vol. 14, No. 70 , p. $3^{-21}$.

Budd, W. F., and McInnes, B. J. 1974. Modeling periodically surging glaciers. Science, Vol. 186, No. 4167, p. $9^{25}-27$.

Budd, W. F., and others. I 979. Empirical studies of ice sliding, by W. F. Budd, P. L. Keage, and N. A. Blundy. Journal of Glaciology, Vol. 23, No. 89, p. i57-70.

\section{PRESSURE-MELTING WITHIN THE BASAL ICE OF AN ALPINE GLACIER INDICATED BY THE CHEMICAL COMPOSITION OF REGELATION ICE}

\author{
By R. Souchez, M. Lemmens, R. Lorrain, and J.-L. Tison \\ (Laboratoire de Géomorphologie, Faculté des Sciences, Université Libre de Bruxelles, \\ Avenue F. D. Roosevelt 50, B-105o Bruxelles, Belgium)
}

Abstract. In the heat-pump effect developed by Robin (1976), pressure-melting within the basal ice mass, as distinct from processes at the ice-bedrock interface, can be responsible for the formation of excess water in zones of high-pressure ice up-stream of obstacles. This water is squeezed out of the ice by the pressure and can refreeze at the interface to form regelation ice down-stream.

The peculiar chemical characteristics of regelation ice at the base of Glacier de Tsijiore Nouve in the Swiss Alps can only be explained by refreezing of this squeezed water. Melting at the interface up-stream of bed protuberances and refreezing of these melt waters downstream, as implied in Weertman's theory, can be excluded in this case.

This paper is published in full in Nature, Vol. 273, No. 5662, 1978, p. 454-56.

\section{REFERENCE}

Robin, G. de Q. 1976. Is the basal ice of a temperate glacier at the pressure melting point? Fournal of Glaciology, Vol. 16 , No. 74 , p. $183-96$.

\section{DISCUSSION}

B. Hallet: What do you think about the possibility of calcium and magnesium carbonates precipitating in basal ice around particles in the ice, thereby providing a sink for their divalent ions and causing relative enrichment of sodium and potassium in the water that is finally incorporated in the regelation ice?

R. A. Souchez: Precipitation of carbonates is precluded for the following reasons: (a) there is no lime coating on particles or on the gneissic bedrock; (b) if carbonate precipitation occurs at depth within the ice around particles, the eutectic calcium concentration in water must be reached. Now, if you take the minimum value for carbon dioxide partial pressure and a rather low distribution coefficient (o.or), regelation ice would have a minimum calcium content of I $3 \mu$ eq $\mathrm{l}^{-1}$. In fact, it has $6.4 \mu$ eq $\mathrm{l}^{-1}$ (mean value), which is smaller by a factor of two. 